\title{
Report From the International Society of Urological Pathology (ISUP) Consultation Conference on Molecular Pathology of Urogenital Cancers
}

\author{
IV: Current and Future Utilization of Molecular-Genetic Tests for \\ Testicular Germ Cell Tumors
}

\author{
Leendert H.J. Looijenga, PhD, * Theodorus H. Van der Kwast, MD, PhD, † David Grignon, MD, $\neq$ \\ Lars Egevad, MD, \& Glen Kristiansen, MD,\| Chia-Sui Kao, MD, $\mid$ and Muhammad T. Idrees, MD\#
}

\begin{abstract}
The International Society of Urological Pathology (ISUP) organized a Consultation Conference in March 2019 dealing with applications of molecular pathology in Urogenital Pathology, including testicular tumors (with a focus on germ cell tumors [GCTs]), preceded by a survey among its members to get insight into current practices in testicular germ cell tumor (TGCT) diagnostics and adoption of the ISUP immunohistochemical guidelines published in 2014. On the basis of the premeeting survey, the most commonly used immunomarker panel includes OCT3/4, placental alkaline phosphate, D2-40, SALL4, CD117, and CD30 for GCTs and the documentation of germ cell neoplasia in situ (GCNIS). Molecular testing, specifically $12 \mathrm{p}$ copy gain, is informative to distinguish non-GCNIS versus GCNIS related GCTs, and establishing germ cell origin of tumors both in the context of primary and metastatic lesions. Other molecular methodologies currently available but not widely utilized for TGCTs include genome-wide and targeted approaches for specific genetic anomalies, P53 mutations, genomic MDM2 amplification, and detection of the p53 inactivating miR-
\end{abstract}

From the *Princess Máxima Center for Pediatric Oncology, Utrecht, The Netherlands; †Laboratory Medicine Program, University Health Network, Toronto, Canada; Departments of $\$$ Pathology and Laboratory Medicine; \#Pathology, Indiana University School of Medicine, Indianapolis, IN; §Department of Oncology and Pathology, Karolinska Institutet Sweden, Solna, Sweden; ॥Department of Pathology, University Hospital Bonn, Bonn, Germany; and $\uparrow$ Department of Pathology, Stanford University School of Medicine, Stanford, CA.

C.-S.K. and M.T.I. shared last authorship.

Conflicts of Interest and Source of Funding: The authors have disclosed that they have no significant relationships with, or financial interest in, any commercial companies pertaining to this article.

Correspondence: Leendert H.J. Looijenga, PhD, Princess Máxima Center for Pediatric Oncology, Utrecht 3084 CS, The Netherlands (e-mail: 1.looijenga@prinsesmaximacentrum.nl).

Supplemental Digital Content is available for this article. Direct URL citations appear in the printed text and are provided in the HTML and PDF versions of this article on the journal's website, www.ajsp. com.

Copyright (C) 2020 The Author(s). Published by Wolters Kluwer Health, Inc. This is an open-access article distributed under the terms of the Creative Commons Attribution-Non Commercial-No Derivatives License 4.0 (CCBY-NC-ND), where it is permissible to download and share the work provided it is properly cited. The work cannot be changed in any way or used commercially without permission from the journal. 371a-3p. The latter also holds promise as a serum marker for malignant TGCTs. This manuscript provides an update on the classification of TGCTs, and describes the current and future role of moleculargenetic testing. The following recommendations are made: (1) Presence of GCNIS should be documented in all cases along with extent of spermatogenesis; (2) Immunohistochemical staining is optional in the following scenarios: identification of GCNIS, distinguishing embryonal carcinoma from seminoma, confirming presence of yolk sac tumor and/or choriocarcinoma, and differentiating spermatocytic tumor from potential mimics; (3) Detection of gain of the short arm of chromosome 12 is diagnostic to differentiate between non-GCNIS versus GCNIS related GCTs and supportive to the germ cell origin of both primary and metastatic tumors.

Key Words: testis, germ cell tumor, guidelines, immunohistochemistry, molecular test, genetic test

(Am J Surg Pathol 2020;44:e66-e79)

T esticular germ cell tumors (TGCTs) represent a highly heterogenous group of neoplasms, including both benign and malignant, displaying a tremendous variety of morphologic elements in pure or mixed forms. On the basis of clinical evidence through various independent confirmatory and multidisciplinary studies, the proposal for a novel GCT classification was accepted at the last Consensus meeting of the World Health Organization (WHO) held in 2015, providing the basis for the new WHO classification (2016)., ${ }^{1,2}$ The most crucial change was the replacement of the nomenclature of intratubular germ cell neoplasia of unclassified type (IGCNU) by germ cell neoplasia in situ (GCNIS), which allowed reclassification of TGCTs in 2 fundamentally different categories: GCNIS associated and non-GCNIS associated TGCTs (Fig. 1). This was a remarkable departure from the former WHO classification and also provided a platform for the potential construction of a molecular/genetic classification. Most malignant TGCTs (type II tumors) originate from GCNIS. In contrast, non-GCNIS-related TGCTs encompass, in fact, 2 distinct types, being the prepubertal-type teratomas/ yolk sac tumors (YSTs) (type I) and spermatocytic tumors (type III) because of different cells of origin and pathogenesis. 


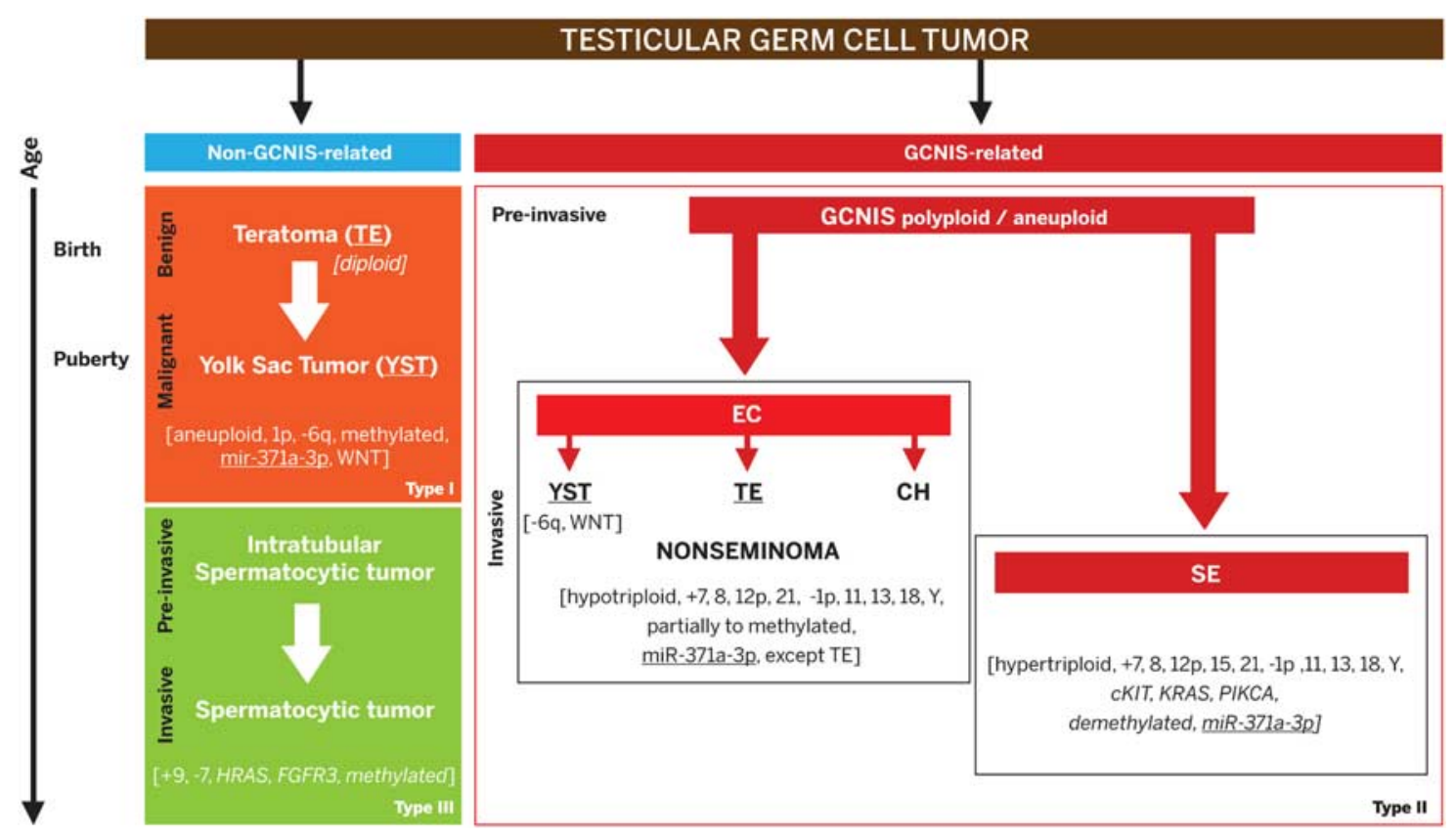

FIGURE 1. Schematic representation of the various entities of TGCTs. The timeline is indicated on the left side. The TGCTs include the non-GCNIS related TGCTs (left panel) and GCNIS-related TGCTs (right panel). The non-GCNIS related TGCTs are subcategorized into the prepubertal TE (being diploid) and YST as well as the spermatocytic tumors. These are also referred to as type I and III, respectively. The GCNIS-related TCCTs are histologically (and clinically) subdivided into the seminomas (SE) and the various elements of nonseminomatous TGCTs, being embryonal carcinoma (EC), YST, choriocarcinoma, and TE. Note the overlapping histology between the prepubertal TE/YST and the TE and YST elements in the GCNIS-related nonseminomas (being underlined). However, they have a separate (and independent) pathogenesis (see text for further details). The precursors are indicated when known (preinvasive), while specifically, the benign and malignant behavior of the pediatric TE and YST is highlighted. Besides, the most prominent and recurrent molecular genetic changes are indicated, of putative interest to be used for molecular pathologic approaches. These include total genomic anomalies, like polyploid/aneuploid, specific chromosomal imbalances like losses ( () , and gains (+), as well; as recurrent mutations (italics). Also, the methylation status is indicated, as well as the possible use of miR-371a-3p as a liquid biopsy molecular biomarker (underlined). All malignant histologic elements, independent of age, are identified by this biomarker (except TE). The WNT pathway is specifically involved in the YST components, independent of age and as such also of pathogenesis.

Recognition of this fundamentally and conceptually different classification system provided an opportunity to identify novel biomarkers for primary (testicular) diagnosis and metastatic or relapsed lesions. It is relevant to indicate that these biomarkers are also informative for ovarian as well as extragonadal GCTs (including mediastinal and sacrococcygeal).

The International Society of Urological Pathology (ISUP) recently organized a Consultation Conference dealing with applications of molecular pathology in Urogenital Pathology, including testicular tumors (heavily focused on TGCTs), preceded by a survey among its members to get insight in current practice and relevant application of molecular methodologies. The members of the testicular working group were identified based on their expertise in the testicular pathology and association with major diagnostic centers. The survey questions were developed after input from the ISUP working group (which also solicited input from Dr Thomas Ulbright from Indiana University for which we are greatly appreciative of his valuable suggestions and insight). After the survey results were collated, the members of the testis working group, with the editorial oversight of ISUP genitourinary experts, came up with the recommendations based on survey results, prior ISUP recommendations, and panel members' diagnostic expertise. This manuscript provides an updated review of TGCT classification and its rationale, describes the current and potential future role of molecular-genetic testing, and discusses evidence and challenges to utilize currently available molecular-genetic tests. Recommendations are provided to practicing pathologists in light of existing evidence, survey results and expert feedback. Since the role of immunohistochemistry (IHC) in the diagnosis of various TGCTs is crucial due to prognostic implications and clinical decision making, the implementation and effectiveness of the ISUP IHC guidelines developed from a similar survey in 2014 was also investigated.

\section{ISUP SURVEY RESULTS FOR TESTICULAR TUMORS}

The survey results are as follows. A total of 256 members of ISUP responded to one or more questions of the survey (Supplementary Table, Supplemental Digital Content 1, http:// links.lww.com/PAS/A911). Only $17 \%$ of 208 respondents processed $>50$ orchiectomy specimens per year, while $12 \%$ evaluated $<10$ orchiectomies per year. 


\section{IHC Survey Results and Discussion}

Among 207 respondents, 32\% routinely used ( $>80 \%$ of cases) IHC for diagnosis of TGCT, while only $5 \%$ never used IHC for this purpose. In total, $47 \%$ of respondents applied the IHC recommendations based on the previous ISUP consultation paper authored by Ulbright et al. ${ }^{3}$ The remaining either did not use or were not aware of them. Overall, 70\% of respondents used IHC for documentation of GCNIS in testicular biopsy using OCT3/4, placental alkaline phosphatase (PLAP), D2-40 (podoplanin), SALL4, and cKIT (CD117), sometimes in combination. OCT3/4 was the most commonly used IHC for documentation of GCNIS $(69 \%)$. In orchiectomy specimens, $49 \%$ utilized IHC for documentation of GCNIS, again OCT3/4 being the most popular biomarker (68\%).

In light of the survey results and for the reader's interest, it is imperative to discuss the role and utilization of IHC stains in the differential diagnosis of TGCTs. A commentary is provided, incorporating the survey results and discussing the use of different IHC markers as outlined in a previously published ISUP article in addition to any recent updates. ${ }^{3}$

OCT3/4 (POU5F1) is the most popular marker used in the identification of GCNIS, especially in biopsy material. Other markers including PLAP, D2-40 (podoplanin), SALL4, and cKIT (CD117), are less commonly used (Supplementary Table, Supplemental Digital Content 1, http://links.lww.com/ PAS/A911). OCT3/4 has been shown to be $100 \%$ sensitive in seminomas, embryonal carcinomas, and GCNIS, and it is perceived as a gatekeeper in developing an algorithm for the differential diagnosis of TGCTs. ${ }^{4,5}$ In addition to GCNIS recognition, its expression narrows the differential diagnosis only to seminoma and embryonal carcinoma, which can be further resolved by a number of IHC markers routinely available in most laboratories. CD117 and CD30 are most helpful in discerning between seminoma and embryonal carcinoma. CD117 is virtually expressed in all seminomas (and GCNIS) while negative in embryonal carcinoma. ${ }^{6}$ CD30 is positive in embryonal carcinoma (up to $100 \%$ ) but negative in seminoma. ${ }^{6}$ Other markers, including podoplanin and SOX17, are expressed in seminoma but are negative in embryonal carcinoma. ${ }^{7,8}$ AE1/AE3 and SOX2 are positive in embryonal carcinoma while negative in seminoma. ${ }^{7}$

OCT3/4 negative TGCTs include YST, choriocarcinoma, and spermatocytic tumor. A limited panel including glypican 3 (GPC3), alpha-fetoprotein (AFP), $\beta$-human chorionic gonadotropin (hCG), and possibly PLAP is most helpful for the distinction of these tumors. GPC3 is a sensitive marker for YST; however, its expression may be observed in up to $80 \%$ of choriocarcinomas. ${ }^{9}$ AFP is specific for YST, but it is less sensitive and often expressed focally when compared with GPC 3. ${ }^{10} \beta$-hCG is sensitive for choriocarcinoma but may be expressed in other nontrophoblastic tumors. ${ }^{11,12}$ PLAP has an overall limited role in germ cell tumor (GCT) distinction as it can be variably positive in most GCTs. ${ }^{13}$ PLAP has fallen out of favor with the increasing availability of overall more sensitive and specific GCT markers such as OCT3/4 and GPC3. Spermatocytic tumor is negative for all the commonly used germ cell markers except CD117, which can be positive in $\sim 40 \%$ of tumors, and is a potential pitfall for misdiagnosis as a seminoma; the lack of OCT3/4 expression can be useful in differentiating between spermatocytic tumor and seminoma. ${ }^{13,14}$

Overall, the subtyping of TGCTs can be achieved by using a limited panel of markers including OCT3/4, CD117, CD30, and GPC3, keeping in mind the potential pitfalls that may be prevented with a careful examination of morphologic features. It is needless to say that morphologic findings alone are sufficient in most cases and IHC should only be utilized in challenging cases. Altered morphology is commonly a result of poor specimen fixation. ${ }^{15}$

In rare instances, the differential diagnosis involves a sex cord stromal tumor. In this setting, SALL4 can be utilized to rule out TGCTs by virtue of its expression in most cases and is particularly useful in TGCT metastases. ${ }^{16}$ Sterogenic factor$1, \alpha$-inhibin, and calretinin can further aid in establishing the diagnosis. If SALL4 is not available, an alternate panel may be used including OCT4, GPC3, $\alpha$-inhibin, and calretinin.

SALL4 is also helpful in discerning other rare tumors occuring in the testis such as lymphomas or metastatic carcinomas from TGCTs. Hematopoietic markers markers, including CD45, CD20, and CD3, should be included in the initial panel for this differential diagnosis. In the setting of possible metastatic carcinoma, SALL4, OCT3/4, and EMA or, alternatively, OCT4, GPC3, EMA, and CK7 may be helpful in the distinction. Other immunostains may be indicated depending on the mophologic features of the tumor, such as PAX8 (for renal primary) or NKX3.1 (for prostate primary).

In summary, appropriate use of IHC stains may aid in the correct subclassification of testicular tumors and it is recommended that OCT3/4, GPC3, and SALL4 should be acquired by the laboratories that often deal with GCTs in their practices. The recommendations presented in previous IHC survey article are still valid; adherence and proper utilization of these recommendations is fundamental in providing accurate diagnosis and best practices in pathology.

\section{Molecular Testing Survey Results and Discussion}

Among 206 respondents, an overwhelming majority (71\%) answered that they never obtained molecular/genetic testing results on testicular specimens either requested by physicians or ordered by the pathologists themselves, while molecular-genetic testing was performed occasionally or rarely by $24 \%$ and $5 \%$, respectively (Supplemental Table, Supplemental Digital Content 1, http://links.lww.com/PAS/A911). The presence of $12 \mathrm{p}$ gain, often in the form of isochromosome $12 \mathrm{p}(\mathrm{i}(12 \mathrm{p}))$ was the most common (77\% of those who ordered) testing performed for testicular specimens. Targeted genomewide mutational profiling, microsatellite instability analyses, and genome-wide DNA copy number variation (CNV) molecular testing were performed in the frequency of $7.5 \%, 2.5 \%$, and $2 \%$, respectively. None of the participants ordered microRNA profiling for clinical use.

Most commonly, i(12p) analysis was performed to confirm TGCT origin in metastatic tumors, especially those with somatic type differentiation and to differentiate between prepubertal versus postpubertal type teratoma. Fluorescent in situ hybridization (FISH) testing was utilized by at least $73 \%$ of the respondents who requested testing. Other methodologies, 
including Oncoscan/single nucleotide polymorphism (SNP) array, next-generation sequencing, and molecular biology, were utilized less frequently. Another $8.6 \%$ of respondents who sent molecular testing to reference laboratories did not specify their methodology. More than two thirds of the FISH testing was performed in house while the remaining was done at outside laboratories or in reference centers.

Targeted gene wide mutational profiling was performed in cases with a differential diagnosis of sex cord-stromal tumor, determination of chemoresistance, to identify targetable genes, comprehensive molecular testing, and testing with a cancer hot spot panel or for research purpose. Microsatellite instability analysis was most commonly done by IHC and less often by other methodologies, particularly in the context of metastatic disease.

When asked about the context of the overall use of molecular testing, the most common indication was to confirm GCNIS and GCNIS derived tumors via gain of $12 p$. The other indications in the descending order were metastatic TGCT, mutational therapy, unknown malignancy, recurrent TGCT, and gene profiling.

In the next paragraphs, a comprehensive summary of the various types of TGCTs will be presented, with the focus on their cell of origin and early pathogenetic changes, possibly resulting in targets for molecular testing.

\section{NON-GCNIS-RELATED (TYPES I AND III) TESTICULAR GCTS}

Non-GCNIS-related TGCTs encompass prepubertaltype teratomas and/or prepubertal-type YST (type I TGCT), predominantly diagnosed at early (pediatric) age, and spermatocytic tumor (type III TGCT), always diagnosed after puberty. Both non-GCNIS (type 1 TGCT, benign) related teratoma and GCNIS related teratomas (type II TGCT, with malignant potential) may occur in the pediatric age group, and for this reason, it is recommended that the terms prepubertaltype teratoma and postpubertal-type teratoma should be used respectively. ${ }^{17}$ Similarly, a prepubertal-type teratoma may rarely occur in an adult, thought to represent a persistent lesion from an earlier age.

YSTs are malignant, independent of whether type I or type II, though type I may have a low incidence of progression. ${ }^{18}$ There is no established cell of origin for prepubertal-type testicular teratoma/YST, but an early embryonic germ or stem cell has been proposed as a possible candidate. ${ }^{19,20}$ The other non-GCNIS-related TGCT is spermatocytic tumor (previously spermatocytic seminoma) (type III TGCT). The nomenclature of the current WHO 2016 classification was adopted to give this entity a distinct label separating it from seminoma and highlight its indolent behavior. There is abundant evidence that spermatocytic tumors originate from a more mature germ cell phenotype, likely a spermatogonium or spermatocyte.

The presence of GCNIS implies a (potentially) malignant type II TGCT. In the case of only atrophic seminiferous tubules, the absence of GCNIS must be interpreted with caution. However, IHC is vital to confirm absence of GCNIS in this situation and classification of type I teratoma. In difficult cases, investigation of the genomic composition (ie, diploid vs. aneuploid) of the teratoma is much more informative. By virtue of its metastatic potential, the presence of a YST in association with teratoma becomes the major predictor of its behavior. ${ }^{21}$ The presence of seminoma, embryonal carcinoma, or choriocarcinoma will establish the diagnosis of GCNIS derived TGCT (type II) and will dictate the clinical management accordingly (see Fig. 1 for decision making). No IHC stain is available to differentiate between a prepubertal-type or postpubertal-type teratoma/YST. In the clinical setting, presence of GCNIS, and evaluation of the molecular genetic composition is more informative for this distinction.

\section{Molecular Genetic Constitution}

No recurrent somatic mutations are identified so far in prepubertal teratomas, ${ }^{22-24}$ including DEAD-END, as a candidate gene from mouse studies. ${ }^{25}$ Although the pediatric teratomas are diploid, aneuploidy is characteristic for pediatric YSTs, showing a specific pattern of imbalances (chromosome 1 [gain], 6q [loss], and part of 12p [gain, in particularly $12 \mathrm{p} 13])^{24,26}$ Possible candidate genes might be STELLA, NANOG, and GDF3, being important in the context of FISH data analyses to differentiate between a non-GCNIS-related and GCNIS-related YST. ${ }^{27,28}$ Besides FISH, evaluation of broad CNVs can be diagnostic as well. Besides gain of (a part of) the short arm of chromosome 12, 6q loss is also characteristic for GCNIS-related YSTs, indicating that it is linked to yolk sac differentiation. ${ }^{29,30}$

Specific CNV can also be detected using other approaches, amongst other polymerase chain reaction based assays, SNP-based or DNA methylation-based arrays. ${ }^{17,31-33}$ Of interest is that a selection of germline SNPs is linked to the formation of pediatric (including testicular) GCTs. They are, in fact, susceptibility alleles, possibly playing a role in their pathogenesis in addition to environmental factors. ${ }^{34,35} \mathrm{Up}$ to now, no genome-wide studies on somatic mutations have been performed, limiting the comparison to the other types of GCTs. ${ }^{36-38}$ A summary is presented in (Fig. $2 \mathrm{Aa}-\mathrm{c}$ and $\mathrm{Ba}-\mathrm{h}$ ).

\section{Recommendations}

Non-GCNIS-related TGCTs should be distinguished from the GCNIS-related ones, in which the absence (or presence) of GCNIS in the background is a helpful feature, and its presence may be confirmed using IHC for OCT3/4. FISH for $12 p$ gain should be performed to facilitate the diagnosis of a prepubertal-type teratoma in postpubertal patients. NonGCNIS-related (benign) teratomas (type I) are diploid without specific genetic anomalies.

\section{SPERMATOCYTIC TUMORS (TYPE III TESTICULAR GCTS)}

The spermatocytic (type III) TGCTs are now renamed as "spermatocytic tumor" in the WHO 2016 classification system, predominantly occurring in elderly men with rare exceptions in younger males. Their distinct pathogenesis has been recently elucidated in great detail. ${ }^{39-46}$ The proposed cell of origin is either a spermatogonium or early primary spermatocyte, based on their cellular composition, RNA, and 


\section{A}
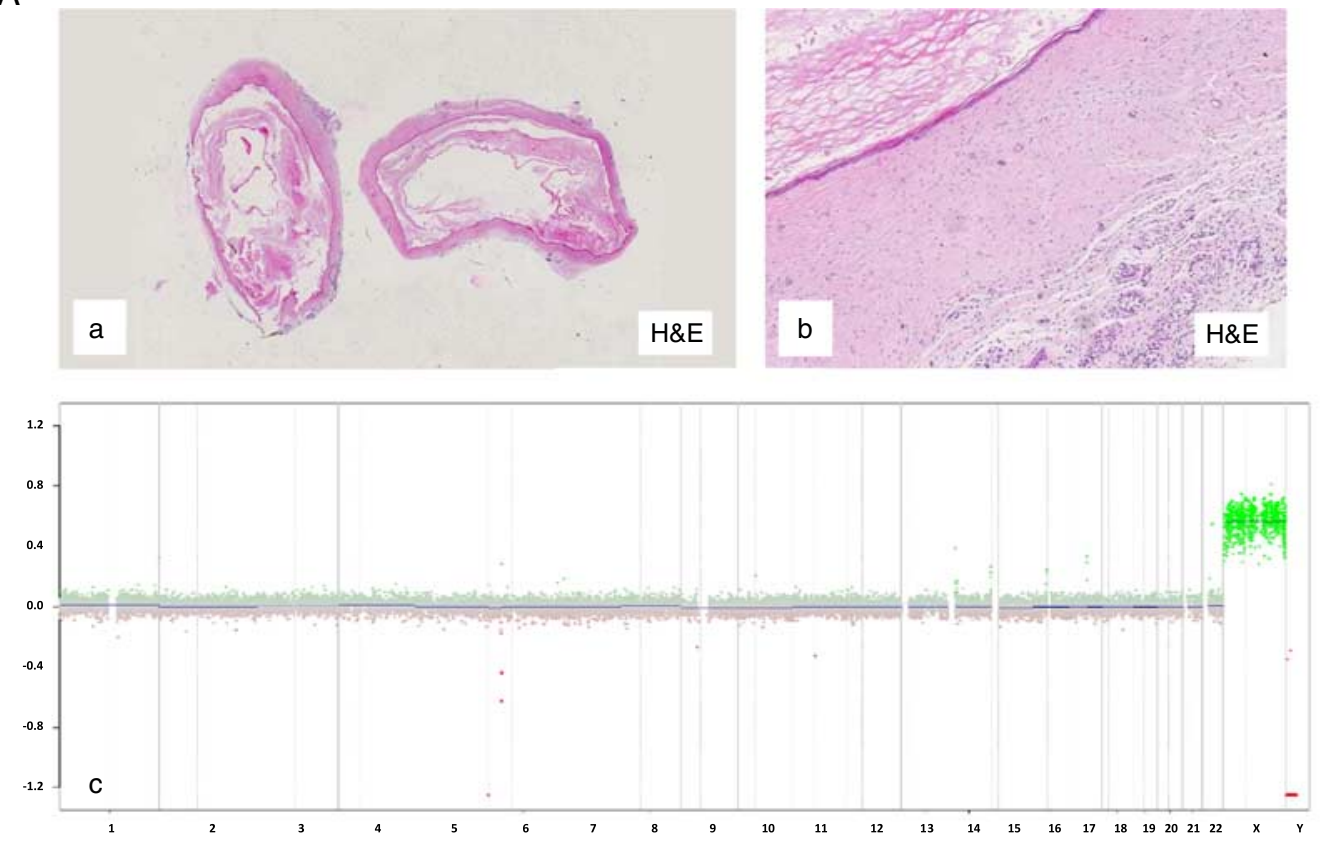

B
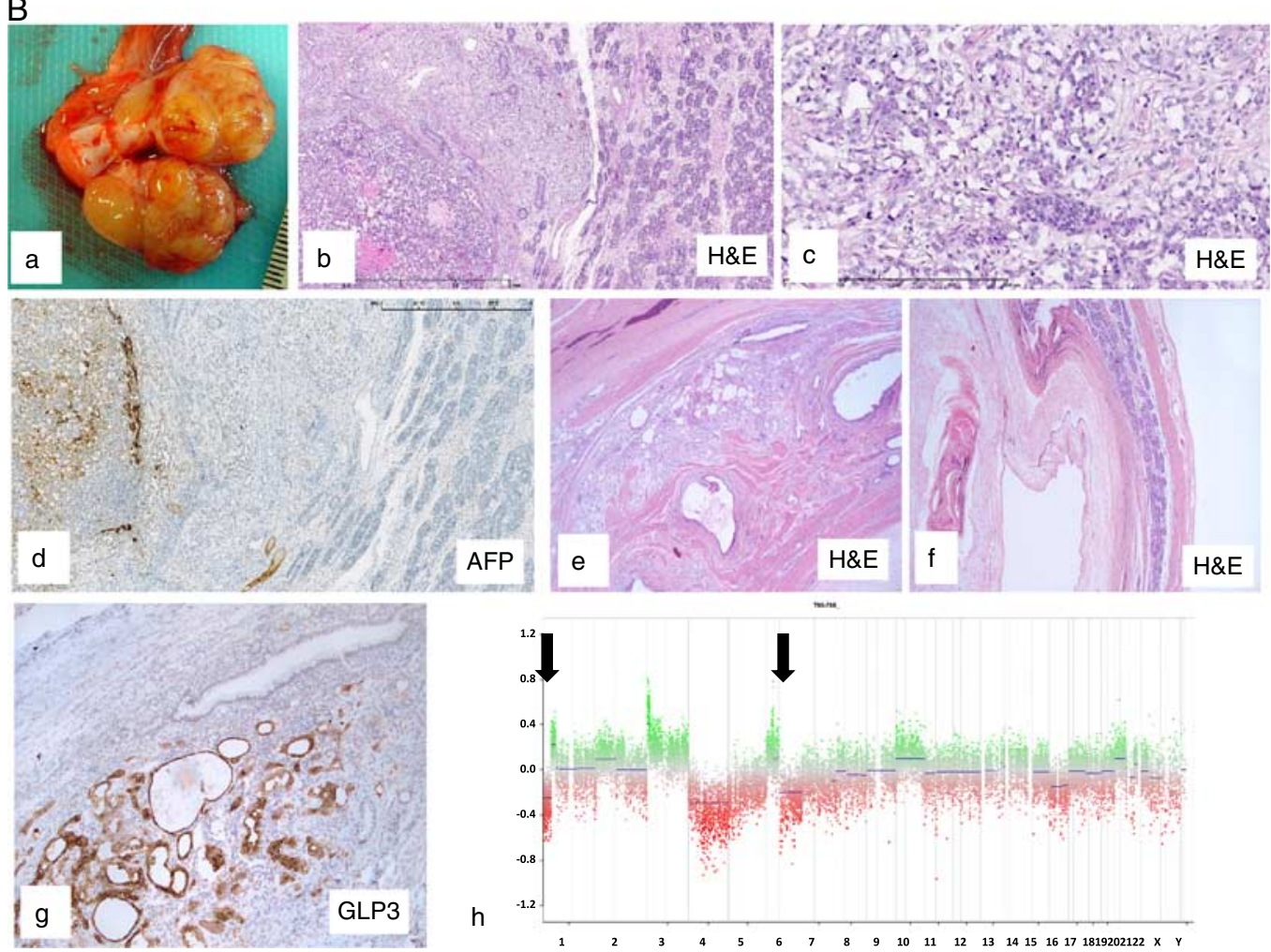

FIGURE 2. A, Microscopic example of a prepubertal pure testicular teratoma ( $3 y$ of age) ( $a, b$, hematoxylin \& eosin [H\&E]) after enucleation to leave the testis function intact (top panel). No GCNIS was demonstrated in the adjacent parenchyma. Also, no chromosomal imbalances were identified using EPIC methylation profiling, transferred to CNV (lower panel) (c); B, Example of a pure prepubertal YST (YST) (7 mo of age) macroscopically (a) as well as microscopically (b, c, H\&E) and IHC for AFP (d). A mixed GCT displaying prepubertal YST admixed with teratoma component in a 4 months old boy (e, f, H\&E). Note immature seminiferous tubules without GCNIS or active spermatogenesis (f). GPC3 highlighted the YST component (g). The chromosomal imbalances are determined based on EPIC methylation profiling data, showing loss of $1 p$ and $6 q$ (right lower panel) (h). 

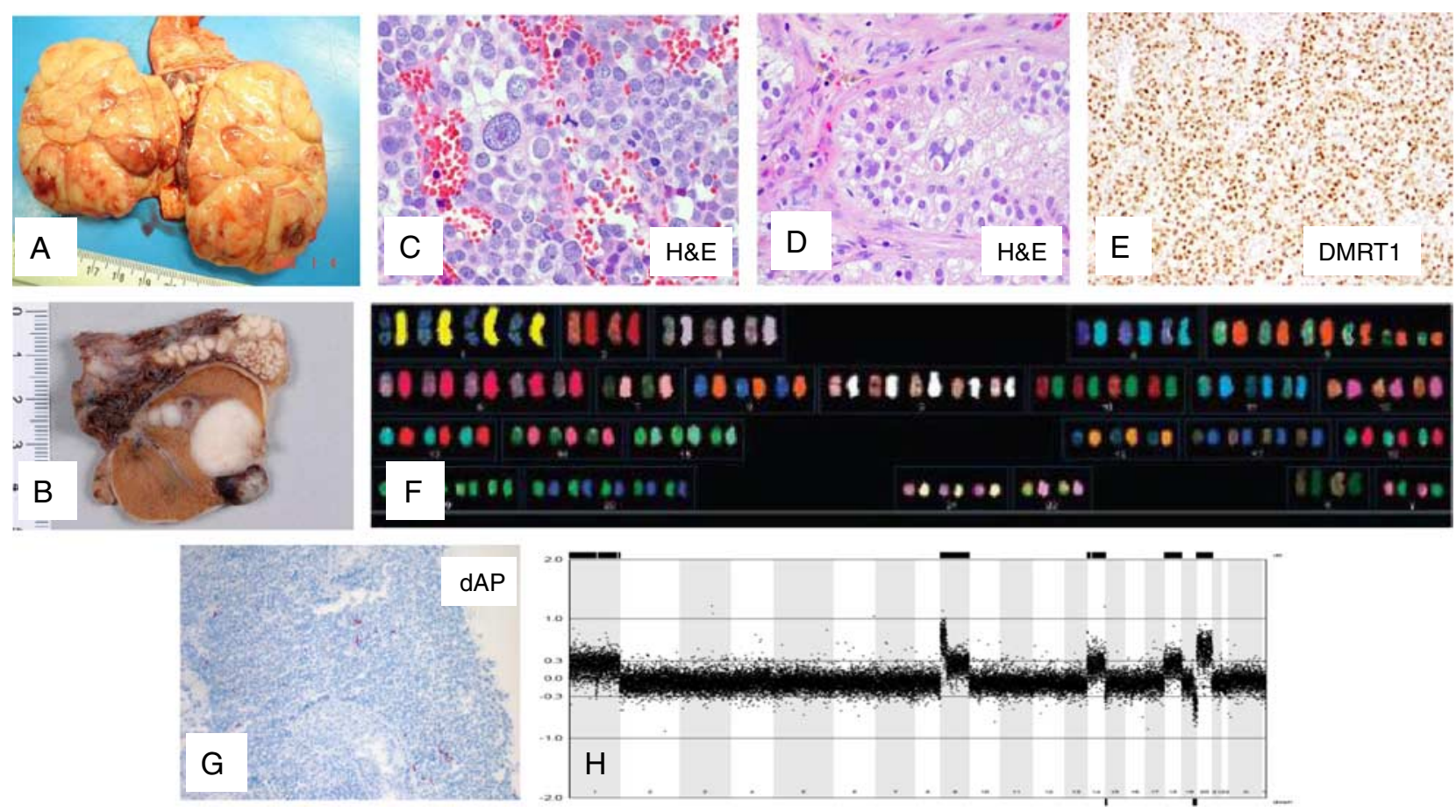

FIGURE 3. Examples of a spermatocytic tumor, macroscopically (A, B), and microscopically (hematoxylin \& eosin [H\&E]) (C, D), and IHC for DMRT1 (E), and direct alkaline phosphatase (dAP) (G). Macroscopically, the tumor appears homogenous on cut surface, whitish to yellow-tan nodular neoplasm replacing the testicular parenchyma, possibly multifocal. Note the unique presence of 3 variants of cells, being small, intermediate, and large. The precursor, known as intratubular spermatocytic tumor, is shown (D). Also, spectral karyotyping (SKY) (F) and array comparative genomic hybridization are shown (H), demonstrated gain of the whole chromosome 9.41

protein profiles. Microscopically these tumors are composed of a polymorphous population of cells with 3 distinct cell types being small, intermediate, and large. Intratubular growth is common, and GCNIS is absent (Fig. 3). Clinically, spermatocytic tumors are indolent unless sarcomatoid transformation is present. ${ }^{47-50}$ The primary differential diagnosis is with seminoma, which has a characteristic immune profile quite different from spermatocytic tumor, as previously discussed. A number of proteins may potentially be useful for the diagnosis of spermatocytic tumors, but not currently used in the clinical setting, include XPA, CYP1, SSX2-4, DMRT1, ${ }^{51}$ CHK2, P53, p16INK4d, MAGE-4A, ${ }^{52}$ OCT2, SAGE1, ${ }^{53}$ NUT, GAGE7, and NY-ESO-12. ${ }^{45}$ In addition, the absence of OCT3/4 is informative to distinguish it from seminoma.

\section{Molecular Genetic Constitution}

Spermatocytic tumors display a unique chromosomal pattern of gains and losses ${ }^{40-42,44,46,54,55}$ in comparison to the other types of TGCT with gain of chromosome 9 present in all cases investigated. DMRT1 overexpression, ${ }^{56}$ mapped on chromosome 9 , is likely related to the consistent gain of this chromosome in spermatocytic tumors. Also, these tumors lack recurrent chromosomal breaks, although they can also show loss of chromosome $7 .^{44,46}$ No somatic mutations have been reported, with the exception of HRAS and FGFR3. The latter are of specific interest because they are also found in spermatogenesis of elderly males, involved in the process known as "selfish spermatogonial selection" favoring expansion of mutated germ cells and rendering germs cells in the offspring of older fathers prone to acquire de novo mutations $^{44,57-59}$ (see below and Fig. 3).

\section{Recommendations}

Spermatocytic tumor is almost always recognizable by morphology alone. IHC can help in challenging cases with unusual morphology, keeping in mind the potential pitfall of CD117 expression (misinterpretation as seminoma) but its lack of OCT3/4 reacitivity.

\section{GCNIS-RELATED TESTICULAR GCTS: TYPE II- HISTOLOGIC DIVERSITY AND CELL OF ORIGIN}

GCNIS, ${ }^{2}$ the precursor lesion of all GCNIS-related TGCTs (also referred to as type II TGCTs) was previously referred to as carcinoma in situ, ${ }^{60}$ IGCNU, or testicular intratubular neoplasia ${ }^{61}$ (Fig. 4). The latest 2016 WHO terminology reflects the nature and pathogenesis of these lesions. GCNIS cells represent a totipotential embryonic germ cell (ie, primordial germ cells/gonocytes) capable of generating all embryological differentiation lineages, including somatic (teratoma, including all 3 germ layers) and extraembryonic (YST and choriocarcinoma). Moreover, initiation of formation of the earliest precursors of germ cell lineage itself can be found in nonseminomas, ${ }^{62}$ representing the circle of life in full perspective, that is, demonstrating its omnipotent character. The 2016 WHO-included overview of diagnostic markers are 

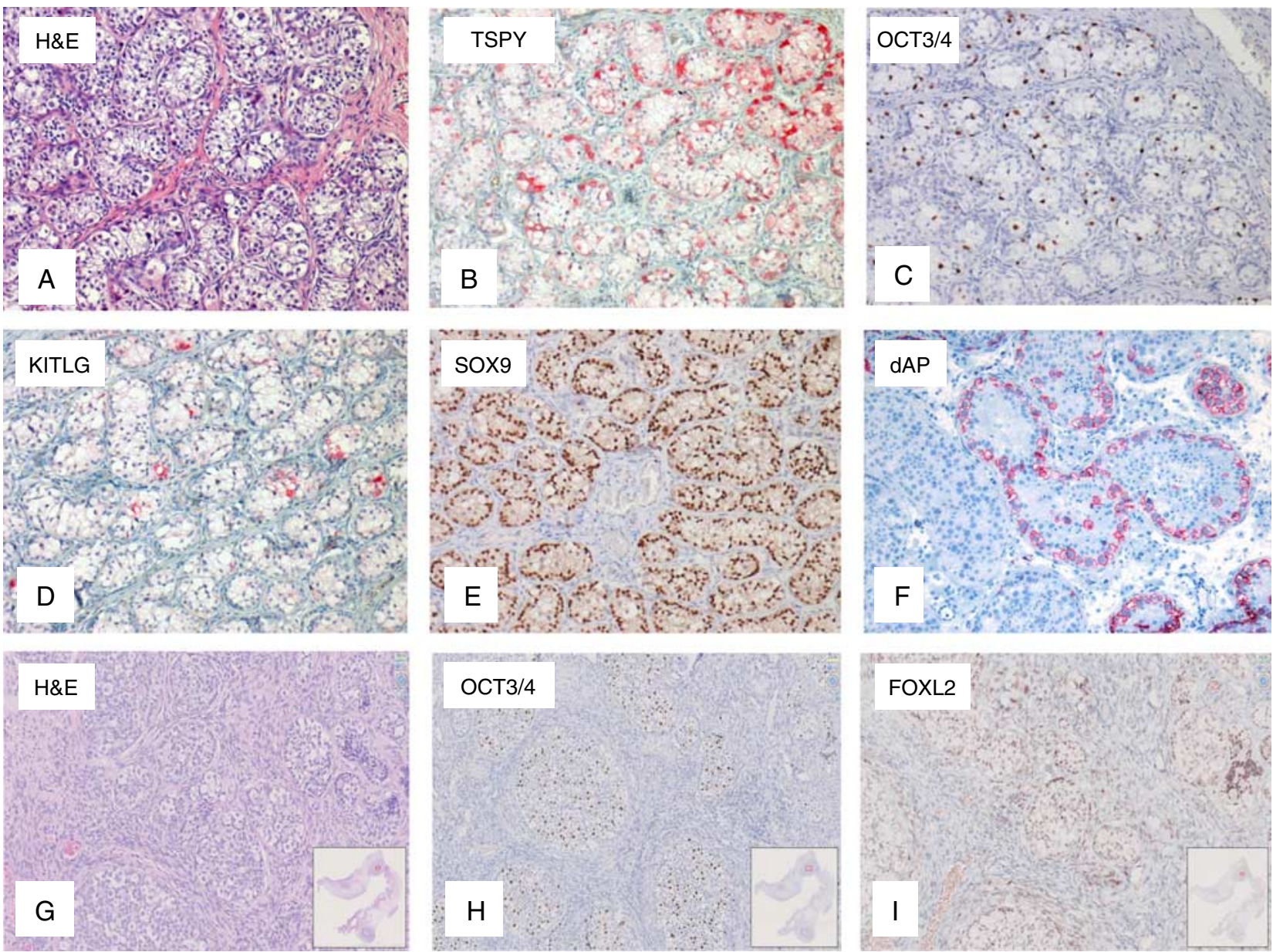

FIGURE 4. Representative examples of GCNIS and gonadoblastoma. GCNIS (top 2 rows) (postpubertal patient with an invasive GCT) stained using hematoxylin \& eosin (H\&E) (A) and IHC for TSPY (B), OCT3/4 (C), KITLG (D), SOX9 (sertoli cell marker, lower magnification) (E), as well as direct alkaline phosphatase (dAP) (F); Gonadoblastoma (lower row) stained using H\&E (G) and IHC for OCT3/4 (H), and (I) FOXL2 (granulosa cell marker). Inset represents the complete overview of the sample slide, the higher magnification area is indicated in the red box.

summarized in Table 1, and representative examples are given in Figure 4. Supplementary Table 1 (Supplemental Digital Content 1, http://links.lww.com/PAS/A911) summarizes the informative proteins to identify the different histologic elements of invasive GCTs, of which representative examples for seminoma and embryonal carcinoma in Figure 5 (being SOX17 and SOX2, in combination with OCT3/4, for seminoma and embryonal carcinoma, respectively) and discussed above in IHC section. ${ }^{63}$ Furthermore, we refer our readers to the series of papers written by ISUP expert panels regarding appropriate IHC utilization for genitourinary tumors, including testicular tumors. $^{64}$

\section{Molecular Genetic Constitution}

Most invasive GCNIS-related TGCTs have overrepresentation of $12 \mathrm{p}$, predominantly as isochromosomes $\mathrm{i}(12 p) .{ }^{65-69} \mathrm{It}$ is absent in GCNIS, and therefore likely required for Sertoli cell-independent survival ${ }^{70}$ (Fig. 6). Seminomas can show high-level amplification of specific subregions of 12, including KRAS. ${ }^{68,73-76}$ Some GCNIS-related GCTs, mostly seminomas, appear to lack a gain of $12 p,{ }^{32,77}$ possibly indicating an alternative pathway (with preferential cKIT mutations). It is thought that GCNIS cells without gain of $12 p$ or cKIT mutations will not progress further to invasive GCT. The $12 \mathrm{p}$ anomalies can be demonstrated by various approaches, including (FISH), SNP array, as well as methylation array (450K or EPIC platform). ${ }^{28,30,31,65,68,74,76,78}$

Several mutational studies, ${ }^{79-82}$ including the most extensive series investigated by the The Cancer Genome Atlas (TCGA) initiative reported by Shen et al, ${ }^{77}$ demonstrate a low mutational burden in TGCT type II independent of histology with only about $\sim 0.1$ to 0.5 somatic changes per Mb. This is in the same range as found in pediatric (non-GCNIS) cancer and spermatocytic tumors (type III). CNV and mutational status analyses indicate that, like for spermatocytic tumors (see above); also 2 variants of seminomas do exist, that is one with and another without KIT mutations, possibly related to the overall level of genome methylation, and gain of $12 p$.

Other mutations or amplification relate to only KRAS, NRAS, and to (even) a lower extent PI3CA. ${ }^{83,84}$ Loss of 
TABLE 1. ISUP Recommendations for Reporting and Molecular Testing Related to Testicular GCTs

$\begin{array}{llc}\text { Topics } & \text { Recommendations } & \text { Remarks }\end{array}$

Application of IHC for final diagnosis 1. Presence of GCNIS must be documented, both in case GCT, and presence of GCNIS in biopsy and orchiectomy specimen of biopsy and orchiectomy

2. IHC is informative to identify GCNIS (ie, using OCT3/4)

3. Seminoma and embryonal carcinoma can be furthe distinguished based on supplemental IHC biomarkers in difficult cases (ie, poor fixation)

4. Overdiagnosis of GCNIS in prepubertal testis (first few years of life) may be avoided using OCT3/4 staining

5. Presence of GB must be checked for, especially in case of nonscrotal testis, and seemingly presence of intratubular seminoma (mimicking GB)

6. Spermatocytic tumor is almost always recognizable via morphology alone; difficult cases can be distinguished using absence of staining for IHC markers typically positive in mimics

7. IHC for AFP/GPC3 and $\beta$-hCG is helpful in confirming presence of YST and choriocarcinoma, respectively

8. SALL4 can be used as surrogate marker for GCT, especially in the setting of unknown history or unusual morphology in metastasis

Performance of molecular testing

1. Molecular testing is informative to distinguish nonGCNIS vs. GCNIS related GCTs (primary and metastatic)

2. Non-GCNIS related (benign) teratomas (type I) are diploid without specific genetic anomalies. This can be detected using (F)ISH, qPCR, as well as other more genome wide approaches ((array) CGH, SNP array, methylation arrays (450K or EPIC)

3. Gain of (the entire) 12p, on top of an overall aneuploid DNA content, is characteristic for most GCNIS related GCTs, both seminomas and nonseminomas, although not for GCNIS itself (although being aneuploid). This can be detected using the techniques mentioned under point 3

4. P53 mutations or genomic MDM2 amplification seem to be the most prominent changes related to treatment resistance of GCNIS related GCT so far. MSI seems to be of limited value. Possibly tumor heterogeneity must be kept in mind

5. Gain of the entire chromosome 9 is characteristic for spermatocytic tumor. This can be detected using the techniques mentioned under point 3

6. cKIT, KRAS, HRAS, and PI3CA are the most frequent mutations, especially found in seminoma (mainly without $12 \mathrm{p}$ )

7. miR-371a-3p (and related family members) is informative to detect malignant GCT components, including YST of the non-GCNIS variant (type I). It can be detected both in tissue as well as body fluids (ie, liquid biopsies)
1. Reporting extent of spermatogenesis is highly recommended. Absence of testicular parenchyma as well as complete lack of spermatogenesis (ie, germ cells) must be specified

2. IHC for OCT3/4 is suboptimal in case of Stieve and Bouin fixatives

3. IHC for OCT3/4 and SOX17 (for seminoma) and OCT3/4, CD30, and SOX2 (embryonal carcinoma). Lymphovascular invasion by embryonal carcinoma is of relevance for risk stratification of stage 1 nonseminomas

4. Morphologic characterization related to specific localization and clonal expansion can be informative, as well as IHC for TSPY and KITLG

5. GB is diagnostic for DSD, implicating GCT risk of contralateral gonad (testis?). IHC for FOXL2 (granulosa cells) is informative (compared with SOX9 of Sertoli cells)

6. Spermatocytic tumor is in principle benign with exception of sarcomatous transformation; bilateral cases do occur

7. No differential diagnostic IHC biomarkers are known for non-GCNIS and GCNIS related YST. Nonchoriocarcinomatous trophoblastic tumors must be considered in DD

8. SALL4 is nonspecific and should be interpreted with caution as other non-germ cell tumors may be positive

1. Precaution has to be taken to include sufficient amount of tumor cells in the final analyses performed

2. Enucleation can be considered in case of absence of GCNIS and a diploid DNA content. Genome wide approaches (see under 3) are most informative; intraoperative consultation may be helpful

3. Genome wide approaches are more informative than a single target-based method

4. Interference with this pathway might be an interesting approach to follow. Again, tumor organoids might be informative

5. Genome wide CNV distinguished seminoma from spermatocytic tumor

6. Interference with this pathway might be an interesting approach to follow

7. Efforts must be performed to prove the value of this molecular test compared with the golden standard AFP and hCG to promote clinical implementation. Liquid biopsy will likely find its usefulness in recent future

Bold indicates the most relevant in clinical practice at this moment.

CGH, comparative genomic hybridization; DD, differential diagnosis; DSD, disorder of sex development; GB, gonadoblastoma; hCG, human chorionic gonadotropin; MSI, microsatellite instability; qPCR, quantitative polymerase chain reaction.

KITLG in nonseminomas is relevant in the context of the assumed cKIT-KITLG loop, either autocrine or paracrine, involved in the earliest stage of pathogenesis. ${ }^{85}$ The identification of amplification of MDM2 is interesting because of the previously reported involvement of the P53/MDM2 axis in therapy resistance. ${ }^{86,87}$ Other putative targets 

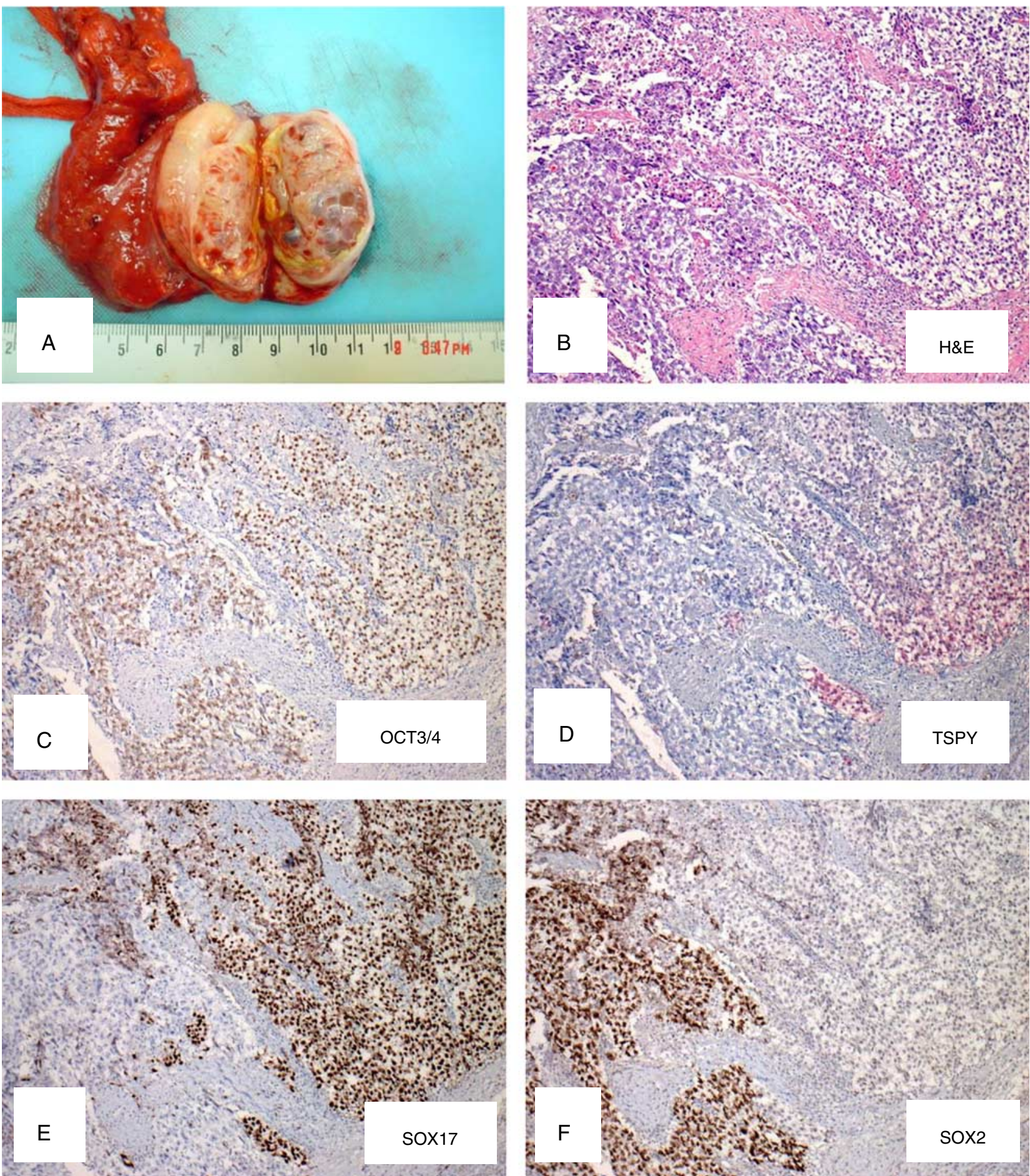

FIGURE 5. Representative example of a mixed germ cell tumor composed of seminoma and embryonal carcinoma (and a small teratoma component and GCNIS [not shown]) (patient 25 y of age) macroscopically (A), stained using hematoxylin \& eosin (H\&E) (B) and IHC for OCT3/4 (C), TSPY (D), SOX17 (highlighting seminoma) (E) and SOX2 (highlighting embryonal carcinoma) (F). No double-positive cells for SOX2 and SOX17 are identified, while all are positive for OCT3/4.

(ie, RAC1 and FAT1) for potential targeted therapy have been reported in limited cases. ${ }^{88,89}$ Although one study related microsatellite instability to cisplatin resistance,,$^{90}$ this was not confirmed in another larger series investigated, possibly due to the selection of predominantly treatment sensitive cases. ${ }^{77}$ The single report on matched GCNIS and invasive nonseminoma elements demonstrated that although the precursor is aneuploid, none of the mutations identified in the invasive lesion 

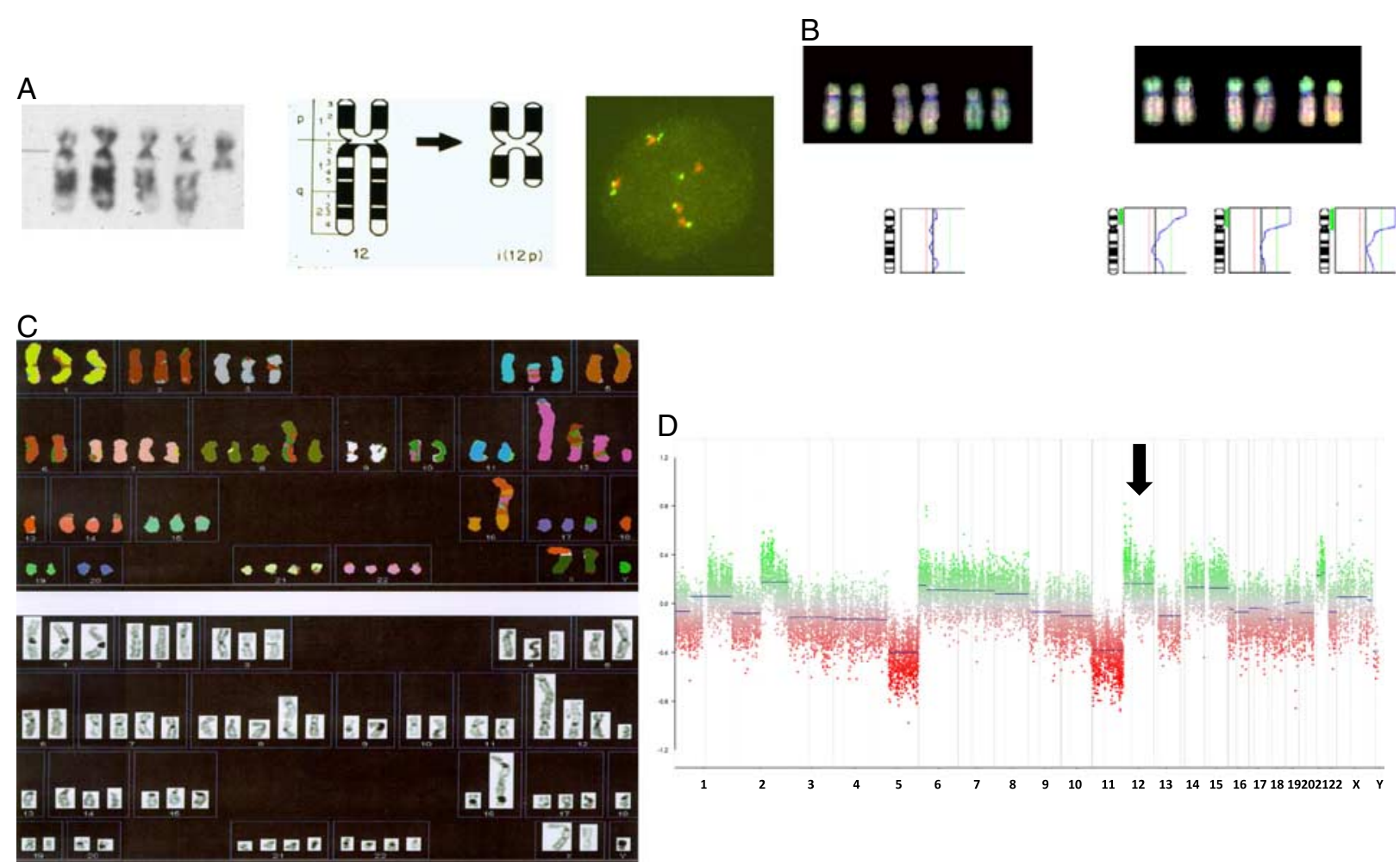

FIGURE 6. Illustrations of chromosomal anomalies (including 12p) as identified by karyotyping and FISH with a centromere-and $12 p$ - specific probes $(A)$. Results of chromosomal comparative genomic hybridization of GCNIS and various invasive components (B), showing the specificity of gain of $12 \mathrm{p}$ for the latter. Also, spectral karyotyping (SKY) of a tumor metaphase spread is shown (C), and an example of CNV (based) based on EPIC methylation profiling is demonstrated (D). ${ }^{71,72}$

were found in the precursors. ${ }^{70}$ This, on the other hand, strongly suggests that mutational load (although low) is progression related.

The resulting model is that GCNIS-related TGCTs are developmental cancers with a disturbed microenvironment. Possibly alterations in the supportive sertoli cells results in a flawed niche inappropriate for full maturation of embryonic germ cells. ${ }^{19,20,91-99}$

\section{Recommendations}

IHC stains may be useful in distinguishing between the different subtypes of malignant TGCTs. Appropriate panels should be selected after the differential diagnosis has been narrowed down to 2 possible entities with careful evaluation of the tumor morphology. Molecular testing is helpful to distinguish between non-GCNIS versus GCNIS related TGCTs, in both primary and metastatic settings, via identification of $12 p$ alterations.

\section{APPLICATION OF miR-371a-3p AS MOLECULAR BIOMARKER FOR MALIGNANT GCTS IN LIQUID BIOPSIES}

The first report on the putative impact of miR-371a-3p as a potential molecular biomarker for GCTs in $2006^{100}$ showed that members of the miR-371-3 family could act as an alternative mechanism for P53 inactivation, resulting in overruling of cellular senescence. This was recently confirmed for all miR-371-3 family members. ${ }^{101}$ High throughput and targeted analyses showed that miR-371a-3p is expressed explicitly in all malignant components of TGCTs, either being type I or II. ${ }^{102-104}$ The molecule was detectable in serum, plasma, and cerebrospinal fluids of patients with malignant TGCT as well as in relevant preclinical models. ${ }^{105-117}$ During adult life, miR-371a-3p is also expressed by normal spermatogonia. ${ }^{118}$ The data available in literature so far show convincingly that miR-371a-3p as molecular liquid biopsy TGCT biomarker is more informative compared with the golden standard AFP and hCG. It is found in all malignant elements, except teratoma. A recent tissue-based study suggested miR-375 to be a potential biomarker for teratoma as well. ${ }^{77}$

\section{Recommendations}

miR-371a-3p (and related family members) is an investigational biomarker to detect malignant TGCT components, including the YST of the non-GCNIS variant (type I) detectable both in tissue as well as body fluids (ie, liquid biopsies).

\section{CONCLUSIONS}

A summary regarding the putative molecular biomarkers of TGCTs is represented in Figure 1. These specifically relate to the various types of TGCTs, being both variants in the non-GCNIS-related and GCNIS-related tumors. CNVs are 
TABLE 2. Molecular Approaches for Possible Future Implications

\section{Molecular Analysis in a Research Context Technique and Possible} Implications

1. Defined SNP profiles are associated with development of GCNIS related (type II) GCTs (supporting an embryonic origin), partly overlapping with the non-GCNIS-related teratomas and YSTs (type I)

2. GCNIS and seminoma are completely demethylated, while the invasive nonseminomas show a lineage specific pattern. DPP3A remained demethylated. Treatment resistant seminomas can be hypermethylated. The XIST promotor is demethylated in GCNIS related GCT of all histologies

3. Mutational load is very low in all GCTs, independent of being GCNIS or non-GCNIS related, while the mutations occurring are related to progression and can be heterogenous (including metastases)

4. HRAS and FGFR3 mutations are detectable in spermatocytic tumor, especially at a later age

5. WNT activation, predominantly related to methylation-based and CNVbased anomaly, is identified in YSTs, both GCNIS and non-GCNIS related (type I and II)

\section{$\operatorname{Remark}(\mathbf{s})$}

1. The power of the SNP profiling indicates that it might only be of clinical value in high risk populations (ie, disorder of sex development and cryptorchidism). It is unknown at which step in the pathogenesis they act on

2. The demethylated DNA pattern might be related to their genomic instability and might offer an alternative target for treatment as well as molecular target for monitoring (both in tissue as well as liquid biopsy)

3. This is likely based on the evolutionary mechanism preventing transmission of mutations to the next generation. Therefore, genome wide approaches to identify hits for targeted treatment is expected to be unsuccessful on primary tumor analyses

4. On the basis of the overall benign behavior, this will not have a clinical impact

5. Preclinical (in vivo) studies need to confirm these findings, in which the use of primary tumor cultures (organoids) might be informative in addition to the limited number of cell lines available

XIST indicates $\mathrm{X}$-inactive specific transcripts.

informative to distinct the types besides histologic composition, specifically, gain of chromosome 12 for the invasive GCNISrelated components and gain of chromosome 9 for the spermatocytic tumors. Aneuploidy and loss of $6 \mathrm{q}$ in the prepubertal YST, in contrast to the prepubertal teratoma, is informative, while all GCNIS-related teratomas are aneuploid and contain gain of $12 p$. The methylation, as well as mutational profiles, are less informative, based on the possible overlap as well as (overall) low frequencies. Of particular interest is the miR-371a$3 p$, found to be highly informative for all malignant (T)GCT components, both in pediatric and (young) adult patients, suitable to be used as liquid-biopsy based molecular biomarker. It is expected that it will change the clinical handling of patients with GCTs of the testis as well as other anatomic localization (extracranial and cranial) drastically within the coming years (Table 2).

It is evident that there has been tremendous progress in the understanding of molecular genetics and biology of TGCTs; however, only limited applications have been translated to patient care currently. This lag is most likely related to the rarity of TGCTS and their overall excellent prognosis. In that context, future evaluation might be more informative to be dedicated to specialized centers of diagnosis and treatment. It is challenging to incorporate much of the recently acquired knowledge into the clinical practice, which further emphasizes that much more effort is required to develop clinically relevant and cost-effective assays.

\section{REFERENCES}

1. Moch H, Cubilla AL, Humphrey PA, et al. The 2016 WHO Classification of Tumours of the Urinary System and Male Genital Organs-Part A: Renal, penile, and testicular tumours. Eur Urol. 2016:70:93-105.

2. Moch H, Humphrey P, Ulbright T, et al. WHO Classification of Tumours of the Urinary System and Male Genital Organs. Lyon, France: IARC; 2016.
3. Ulbright TM, Tickoo SK, Berney DM, et al. Best practices recommendations in the application of immunohistochemistry in testicular tumors: report from the International Society of Urological Pathology consensus conference. Am J Surg Pathol. 2014; 38:e50-e59.

4. Looijenga LH, Stoop H, de Leeuw HP, et al. POU5F1 (OCT3/4) identifies cells with pluripotent potential in human germ cell tumors. Cancer Res. 2003;63:2244-2250.

5. Jones TD, Ulbright TM, Eble JN, et al. OCT4 staining in testicular tumors: a sensitive and specific marker for seminoma and embryonal carcinoma. Am J Surg Pathol. 2004;28:935-940.

6. Lau SK, Weiss LM, Chu PG. D2-40 immunohistochemistry in the differential diagnosis of seminoma and embryonal carcinoma: a comparative immunohistochemical study with KIT (CD117) and CD30. Mod Pathol. 2007;20:320-325.

7. Nonaka D. Differential expression of SOX2 and SOX17 in testicular germ cell tumors. Am J Clin Pathol. 2009;131:731-736.

8. Idrees M, Saxena R, Cheng L, et al. Podoplanin, a novel marker for seminoma: a comparison study evaluating immunohistochemical expression of podoplanin and OCT3/4. Ann Diagn Pathol. 2010;14: 331-336.

9. Zynger DL, Dimov ND, Luan C, et al. Glypican 3: a novel marker in testicular germ cell tumors. Am J Surg Pathol. 2006;30:1570-1575.

10. Zynger DL, McCallum JC, Luan C, et al. Glypican 3 has a higher sensitivity than alpha-fetoprotein for testicular and ovarian yolk sac tumour: immunohistochemical investigation with analysis of histological growth patterns. Histopathology. 2010;56:750-757.

11. Caillaud JM, Bellet D, Carlu C, et al. Immunohistochemistry of germ cell tumors of the testis. Study of beta HCG and AFP. Prog Clin Biol Res. 1985;203:139-140.

12. Demirtas E, Krishnamurthy S, Tulandi T. Elevated serum betahuman chorionic gonadotropin in nonpregnant conditions. Obstet Gynecol Surv. 2007;62:675-679; quiz 691.

13. Niehans GA, Manivel JC, Copland GT, et al. Immunohistochemistry of germ cell and trophoblastic neoplasms. Cancer. 1988;62:1113-1123.

14. Kraggerud SM, Berner A, Bryne M, et al. Spermatocytic seminoma as compared to classical seminoma: an immunohistochemical and DNA flow cytometric study. APMIS. 1999;107:297-302.

15. Verrill C, Yilmaz A, Srigley JR, et al. Reporting and staging of testicular germ cell tumors: The International Society of Urological Pathology (ISUP) Testicular Cancer Consultation Conference Recommendations. Am J Surg Pathol. 2017;41:e22-e32.

16. Cao D, Humphrey PA, Allan RW. SALL4 is a novel sensitive and specific marker for metastatic germ cell tumors, with particular 
utility in detection of metastatic yolk sac tumors. Cancer. 2009; 115:2640-2651.

17. Amatruda JF, Ross JA, Christensen B, et al. DNA methylation analysis reveals distinct methylation signatures in pediatric germ cell tumors. BMC Cancer. 2013;13:313.

18. Lee SD. Korean Society of Pediatric Urology. Epidemiological and clinical behavior of prepubertal testicular tumors in Korea. $J$ Urol. 2004;172:674-678.

19. Oosterhuis J, Looijenga LHJ. Germ, cell tumors: pathology and genetics. In: Boffetta P, Hainaut P, eds. Encyclopedia of Cancer. Oxford, UK: Elsevier Inc.; 2019:121-153.

20. Oosterhuis JW, Looijenga LHJ. Germ cell tumors from a developmental perspective. Nat Rev Cancer. 2019;19:522-537.

21. Harms D, Zahn S, Gobel U, et al. Pathology and molecular biology of teratomas in childhood and adolescence. Klin Padiatr. 2006;218: 296-302.

22. Oosterhuis JW, Looijenga LH, van Echten J, et al. Chromosomal constitution and developmental potential of human germ cell tumors and teratomas. Cancer Genet Cytogenet. 1997;95:96-102.

23. Cornejo KM, Cheng L, Church A, et al. Chromosome $12 \mathrm{p}$ abnormalities and IMP3 expression in prepubertal pure testicular teratomas. Hum Pathol. 2016;49:54-60.

24. Mostert M, Rosenberg C, Stoop H, et al. Comparative genomic and in situ hybridization of germ cell tumors of the infantile testis. $L a b$ Invest. 2000;80:1055-1064.

25. Linger R, Dudakia D, Huddart R, et al. Analysis of the DND1 gene in men with sporadic and familial testicular germ cell tumors. Genes Chromosomes Cancer. 2008;47:247-252.

26. Perlman EJ, Hu J, Ho D, et al. Genetic analysis of childhood endodermal sinus tumors by comparative genomic hybridization. $J$ Pediatr Hematol Oncol. 2000;22:100-105.

27. Perlman EJ, Valentine MB, Griffin CA, et al. Deletion of 1p36 in childhood endodermal sinus tumors by two-color fluorescence in situ hybridization: a pediatric oncology group study. Genes Chromosomes Cancer. 1996;16:15-20.

28. Mostert MM, van de Pol M, van Echten J, et al. Fluorescence in situ hybridization-based approaches for detection of $12 p$ overrepresentation, in particular $\mathrm{i}(12 \mathrm{p})$, in cell lines of human testicular germ cell tumors of adults. Cancer Genet Cytogenet. 1996;87:95-102.

29. Looijenga LH, Rosenberg C, van Gurp RJ, et al. Comparative genomic hybridization of microdissected samples from different stages in the development of a seminoma and a non-seminoma. $J$ Pathol. 2000;191:187-192.

30. Killian LCJD, Trabert B, Gillis AJM, et al. Imprints and DPPA3 are bypassed during pluripotency- and differentiation-coupled methylation reprogramming in testicular germ cell tumors. Genome Res. 2016;26:1490-1504.

31. Malek NP, Casper J, Looijenga LH, et al. Quantification of additional short arms of chromosome 12 in germ cell tumours using the polymerase chain reaction. Eur J Cancer. 1997;33:1488-1494.

32. Killian JK, Dorssers LC, Trabert B, et al. Imprints and DPPA3 are bypassed during pluripotency- and differentiation-coupled methylation reprogramming in testicular germ cell tumors. Genome Res. 2016;26:1490-1504.

33. LeBron C, Pal P, Brait M, et al. Genome-wide analysis of genetic alterations in testicular primary seminoma using high resolution single nucleotide polymorphism arrays. Genomics. 2011;97:341-349.

34. Poynter JN, Hooten AJ, Frazier AL, et al. Associations between variants in KITLG, SPRY4, BAK1, and DMRT1 and pediatric germ cell tumors. Genes Chromosomes Cancer. 2012;51:266-271.

35. Marcotte EL, Pankratz N, Amatruda JF, et al. Variants in BAK1, SPRY4, and GAB2 are associated with pediatric germ cell tumors: a report from the children's oncology group. Genes Chromosomes Cancer. 2017;56:548-558.

36. Sakumi K. Germline mutation: de novo mutation in reproductive lineage cells. Genes Genet Syst. 2019;94:3-12.

37. Ju YS, Martincorena I, Gerstung M, et al. Somatic mutations reveal asymmetric cellular dynamics in the early human embryo. Nature. 2017;543:714-718.

38. Moorjani P, Gao Z, Przeworski M. Human germline mutation and the erratic evolutionary clock. PLoS Biol. 2016;14:e2000744.
39. Rosai J, Silber I, Khodadoust K. Spermatocytic seminoma. I. Clinicopathologic study of six cases and review of the literature. Cancer. 1969;24:92-102.

40. Oosterhuis JW, Castedo SM, de Jong B, et al. Ploidy of primary germ cell tumors of the testis. Pathogenetic and clinical relevance. Lab Invest. 1989;60:14-21.

41. Looijenga LH, Hersmus R, Gillis AJ, et al. Genomic and expression profiling of human spermatocytic seminomas: primary spermatocyte as tumorigenic precursor and DMRT1 as candidate chromosome 9 gene. Cancer Res. 2006;66:290-302.

42. Looijenga LH, Stoop H, Hersmus R, et al. Genomic and expression profiling of human spermatocytic seminomas: pathogenetic implications. Int J Androl. 2007;30:328-335; discussion 335-336.

43. Looijenga LH, Gillis AJ, Stoop HJ, et al. Chromosomes and expression in human testicular germ-cell tumors: insight into their cell of origin and pathogenesis. Ann N Y Acad Sci. 2007;1120:187-214.

44. Giannoulatou E, McVean G, Taylor IB, et al. Contributions of intrinsic mutation rate and selfish selection to levels of de novo HRAS mutations in the paternal germline. Proc Natl Acad Sci USA. 2013;110:20152-20157.

45. Kao CS, Badve SS, Ulbright TM. The utility of immunostaining for NUT, GAGE7 and NY-ESO-1 in the diagnosis of spermatocytic seminoma. Histopathology. 2014;65:35-44.

46. Giannoulatou E, Maher GJ, Ding Z, et al. Whole-genome sequencing of spermatocytic tumors provides insights into the mutational processes operating in the male germline. PLoS One. 2017;12:e0178169.

47. Matoska J, Ondrus D, Hornak M. Metastatic spermatocytic seminoma. A case report with light microscopic, ultrastructural, and immunohistochemical findings. Cancer. 1988;62:1197-1201.

48. Wang PY, Hsieh FY, Cheng TY. Atypical presentations of tuberculous meningitis - a case report. Zhonghua Yi Xue Za Zhi (Taipei). 1991;48:153-157.

49. Menon S, Karpate A, Desai S. Spermatocytic seminoma with rhabdomyosarcomatous differentiation: a case report with a review of the literature. J Cancer Res Ther. 2009;5:213-215.

50. Pandey V, Khatib Y, Khade AL, et al. Spermatocytic seminoma with rhabdomyoblastic differentiation: case report and review of literature. Indian J Pathol Microbiol. 2018;61:437-439.

51. Stoop H, van Gurp R, de Krijger R, et al. Reactivity of germ cell maturation stage-specific markers in spermatocytic seminoma: diagnostic and etiological implications. Lab Invest. 2001;81:919-928.

52. Rajpert-De Meyts E, Jacobsen GK, Bartkova J, et al. The immunohistochemical expression pattern of Chk2, p53, p19INK4d, MAGE-A4 and other selected antigens provides new evidence for the premeiotic origin of spermatocytic seminoma. Histopathology. 2003;42:217-226.

53. Lim J, Goriely A, Turner GD, et al. OCT2, SSX and SAGE1 reveal the phenotypic heterogeneity of spermatocytic seminoma reflecting distinct subpopulations of spermatogonia. J Pathol. 2011;224:473-483.

54. Rosenberg C, Mostert MC, Schut TB, et al. Chromosomal constitution of human spermatocytic seminomas: comparative genomic hybridization supported by conventional and interphase cytogenetics. Genes Chromosomes Cancer. 1998;23:286-291.

55. Looijenga LH. Spermatocytic seminoma: toward further understanding of pathogenesis. $J$ Pathol. 2011;224:431-433.

56. Krentz AD, Murphy MW, Kim S, et al. The DM domain protein DMRT1 is a dose-sensitive regulator of fetal germ cell proliferation and pluripotency. Proc Natl Acad Sci USA. 2009;106:22323-22328.

57. Lim J, Maher GJ, Turner GD, et al. Selfish spermatogonial selection: evidence from an immunohistochemical screen in testes of elderly men. PLoS One. 2012;7:e42382.

58. Maher GJ, Goriely A, Wilkie AO. Cellular evidence for selfish spermatogonial selection in aged human testes. Andrology. 2014;2: 304-314.

59. Maher GJ, Ralph HK, Ding Z, et al. Selfish mutations dysregulating RAS-MAPK signaling are pervasive in aged human testes. Genome Res. 2018;28:1779-1790.

60. Skakkebaek NE. Possible carcinoma-in-situ of the testis. Lancet. 1972;2:516-517.

61. Berney DM, Looijenga LH, Idrees M, et al. Germ cell neoplasia in situ (GCNIS): evolution of the current nomenclature for testicular pre-invasive germ cell malignancy. Histopathology. 2016;69:7-10. 
62. Honecker F, Stoop H, Mayer F, et al. Germ cell lineage differentiation in non-seminomatous germ cell tumours. J Pathol. 2006;208:395-400.

63. De Jong J, Stoop H, Gillis AJ, et al. Differential expression of SOX17 and SOX2 in germ cells and stem cells has biological and clinical implications. J Pathol. 2008;215:21-30.

64. Amin MB, Epstein JI, Ulbright TM, et al. Best practices recommendations in the application of immunohistochemistry in urologic pathology: report from the International Society of Urological Pathology consensus conference. Am J Surg Pathol. 2014; 38:1017-1022.

65. Atkin NB, Baker MC. Specific chromosome change, i(12p), in testicular tumours? Lancet. 1982;2:1349.

66. Van Echten J, Oosterhuis JW, Looijenga LH, et al. No recurrent structural abnormalities apart from $\mathrm{i}(12 \mathrm{p})$ in primary germ cell tumors of the adult testis. Genes Chromosomes Cancer. 1995;14:133-144.

67. Mostert MM, van de Pol M, Olde Weghuis D, et al. Comparative genomic hybridization of germ cell tumors of the adult testis: confirmation of karyotypic findings and identification of a $12 \mathrm{p}$ amplicon. Cancer Genet Cytogenet. 1996;89:146-152.

68. Zafarana G, Gillis AJ, van Gurp RJ, et al. Coamplification of DAD-R, SOX5, and EKI1 in human testicular seminomas, with specific overexpression of DAD-R, correlates with reduced levels of apoptosis and earlier clinical manifestation. Cancer Res. 2002;62: $1822-1831$.

69. Clark AT, Rodriguez RT, Bodnar MS, et al. Human STELLAR, NANOG, and GDF3 genes are expressed in pluripotent cells and map to chromosome 12p13, a hotspot for teratocarcinoma. Stem Cells. 2004;22:169-179.

70. Dorssers LCJ, Gillis AJM, Stoop H, et al. Molecular heterogeneity and early metastatic clone selection in testicular germ cell cancer development. Br J Cancer. 2019;120:444-452.

71. Mostert MC, Verkerk AJ, van de Pol M, et al. Identification of the critical region of $12 p$ over-representation in testicular germ cell tumors of adolescents and adults. Oncogene. 1998;16:2617-2627.

72. Rosenberg C, Van Gurp RJ, Geelen E, et al. Overrepresentation of the short arm of chromosome 12 is related to invasive growth of human testicular seminomas and nonseminomas. Oncogene. 2000;19: 5858-5862.

73. McIntyre A, Summersgill B, Jafer O, et al. Defining minimum genomic regions of imbalance involved in testicular germ cell tumors of adolescents and adults through genome wide microarray analysis of cDNA clones. Oncogene. 2004;23:9142-9147.

74. Zafarana G, Grygalewicz B, Gillis AJ, et al. 12p-amplicon structure analysis in testicular germ cell tumors of adolescents and adults by array CGH. Oncogene. 2003;22:7695-7701.

75. Looijenga LH, Zafarana G, Grygalewicz B, et al. Role of gain of $12 \mathrm{p}$ in germ cell tumour development. APMIS. 2003;111:161-171; discussion 172-173.

76. Roelofs H, Mostert MC, Pompe K, et al. Restricted 12p amplification and RAS mutation in human germ cell tumors of the adult testis. Am J Pathol. 2000;157:1155-1166.

77. Shen H, Shih J, Hollern DP, et al. Integrated molecular characterization of testicular germ cell tumors. Cell Rep. 2018;23:3392-3406.

78. Rodriguez S, Jafer O, Goker H, et al. Expression profile of genes from $12 p$ in testicular germ cell tumors of adolescents and adults associated with $\mathrm{i}(12 \mathrm{p})$ and amplification at $12 \mathrm{p} 11.2-\mathrm{p} 12.1$. Oncogene. 2003;22:1880-1891.

79. Litchfield K, Loveday C, Levy M, et al. Large-scale sequencing of testicular germ cell tumour (TGCT) cases excludes major TGCT predisposition gene. Eur Urol. 2018;73:828-831

80. Litchfield K, Summersgill B, Yost S, et al. Whole-exome sequencing reveals the mutational spectrum of testicular germ cell tumours. Nat Commun. 2015;6:5973.

81. Taylor-Weiner A, Zack T, O'Donnell E, et al. Genomic evolution and chemoresistance in germ-cell tumours. Nature. 2016;540:114-118.

82. Cutcutache I, Suzuki Y, Tan IB, et al. Exome-wide sequencing shows low mutation rates and identifies novel mutated genes in seminomas. Eur Urol. 2015;68:77-83.

83. Goddard NC, McIntyre A, Summersgill B, et al. KIT and RAS signalling pathways in testicular germ cell tumours: new data and a review of the literature. Int $J$ Androl. 2007;30:337-348; discussion 349.

84. McIntyre A, Summersgill B, Grygalewicz B, et al. Amplification and overexpression of the KIT gene is associated with progression in the seminoma subtype of testicular germ cell tumors of adolescents and adults. Cancer Res. 2005;65:8085-8089.

85. Samaniego F, Rodriguez E, Houldsworth J, et al. Cytogenetic and molecular analysis of human male germ cell tumors: chromosome 12 abnormalities and gene amplification. Genes Chromosomes Cancer. 1990;1:289-300.

86. Rijlaarsdam MA, Rijlaarsdam DJ, Gillis AJ, et al. miMsg: a target enrichment algorithm for predicted miR-mRNA interactions based on relative ranking of matched expression data. Bioinformatics. 2013;29:1638-1646.

87. Bagrodia A, Lee BH, Lee W, et al. Genetic determinants of cisplatin resistance in patients with advanced germ cell tumors. $J$ Clin Oncol. 2016;34:4000-4007.

88. Bauer S, Muhlenberg T, Leahy M, et al. Therapeutic potential of MDM2 inhibition in malignant germ cell tumours. Eur Urol. 2010; 57:679-687.

89. Koster R, Timmer-Bosscha H, Bischoff R, et al. Disruption of the MDM2-p53 interaction strongly potentiates p53-dependent apoptosis in cisplatin-resistant human testicular carcinoma cells via the Fas/FasL pathway. Cell Death Dis. 2011;2:e148.

90. Honecker F, Wermann H, Mayer F, et al. Microsatellite instability, mismatch repair deficiency, and BRAF mutation in treatmentresistant germ cell tumors. J Clin Oncol. 2009;27:2129-2136.

91. Looijenga LH, Oosterhuis JW. Pathogenesis of testicular germ cell tumours. Rev Reprod. 1999;4:90-100.

92. Looijenga LH, Oosterhuis JW. Pathobiology of testicular germ cell tumors: views and news. Anal Quant Cytol Histol. 2002;24:263-279.

93. Oosterhuis JW, Looijenga LH. Testicular germ-cell tumours in a broader perspective. Nat Rev Cancer. 2005;5:210-222.

94. Cools M, Wolffenbuttel KP, Drop SL, et al. Gonadal development and tumor formation at the crossroads of male and female sex determination. Sex Dev. 2011;5:167-180.

95. Van Der Zwan YG, Stoop H, Rossello F, et al. Role of epigenetics in the etiology of germ cell cancer. Int J Dev Biol. 2013;57:299-308.

96. Looijenga LH, Van Agthoven T, Biermann K. Development of malignant germ cells - the genvironmental hypothesis. Int J Dev Biol. 2013;57:241-253

97. Rijlaarsdam MA, Looijenga LH. An oncofetal and developmental perspective on testicular germ cell cancer. Semin Cancer Biol. 2014;29: 59-74.

98. Cheng L, Albers P, Berney DM, et al. Testicular cancer. Nat Rev Dis Primers. 2018;4:29.

99. Lobo J, Gillis AJM, Jeronimo C, et al. Human germ cell tumors are developmental cancers: impact of epigenetics on pathobiology and clinic. Int J Mol Sci. 2019;20:258.

100. Voorhoeve PM, Le Sage C, Schrier M, et al. A genetic screen implicates miRNA-372 and miRNA-373 as oncogenes in testicular germ cell tumors. Cell. 2006;124:1169-1181.

101. Bae YU, Son Y, Kim CH, et al. Embryonic stem cell-derived mmumiR-291a-3p inhibits cellular senescence in human dermal fibroblasts through the TGF-receptor 2 pathway. J Gerontol A Biol Sci Med Sci. 2019;74:1359-1367.

102. Gillis AJ, Stoop HJ, Hersmus R, et al. High-throughput microRNAome analysis in human germ cell tumours. $J$ Pathol. 2007;213:319-328.

103. Rijlaarsdam MA, van Agthoven T, Gillis AJ, et al. Identification of known and novel germ cell cancer-specific (embryonic) miRs in serum by high-throughput profiling. Andrology. 2015;3:85-91.

104. Vilela-Salgueiro B, Barros-Silva D, Lobo J, et al. Germ cell tumour subtypes display differential expression of microRNA371a-3p. Philos Trans $R$ Soc Lond B Biol Sci. 2018;373:1748.

105. Gillis AJ, Rijlaarsdam MA, Eini R, et al. Targeted serum miRNA (TSmiR) test for diagnosis and follow-up of (testicular) germ cell cancer patients: a proof of principle. Mol Oncol. 2013;7:1083-1092.

106. Murray MJ, Bell E, Raby KL, et al. A pipeline to quantify serum and cerebrospinal fluid microRNAs for diagnosis and detection of relapse in paediatric malignant germ-cell tumours. $\mathrm{Br} J$ Cancer. 2016;114:151-162. 
107. Murray MJ, Coleman N. Testicular cancer: a new generation of biomarkers for malignant germ cell tumours. Nat Rev Urol. 2012; 9:298-300.

108. Leao R, van Agthoven T, Figueiredo A, et al. Serum miRNA predicts viable disease after chemotherapy in patients with testicular nonseminoma germ cell tumor. J Urol. 2018;200:126-135.

109. Mego M, van Agthoven T, Gronesova P, et al. Clinical utility of plasma miR-371a-3p in germ cell tumors. $J$ Cell Mol Med. 2019;23: $1128-1136$.

110. Salvatori DCF, Dorssers LCJ, Gillis AJM, et al. The microRNA371 family as plasma biomarkers for monitoring undifferentiated and potentially malignant human pluripotent stem cells in teratoma assays. Stem Cell Reports. 2018;11:1493-1505.

111. Van Agthoven T, Eijkenboom WMH, Looijenga LHJ. microRNA-371a-3p as informative biomarker for the follow-up of testicular germ cell cancer patients. Cell Oncol (Dordr). 2017;40: 379-388.

112. Van Agthoven T, Looijenga LH. Accurate primary germ cell cancer diagnosis using serum based microRNA detection (ampTSmiR test). Oncotarget. 2016;8:58037-58049.
113. Spiekermann M, Belge G, Winter N, et al. MicroRNA miR-371a-3p in serum of patients with germ cell tumours: evaluations for establishing a serum biomarker. Andrology. 2015;3:78-84.

114. Dieckmann KP, Spiekermann M, Balks T, et al. MicroRNA miR$371 a-3 p-a$ novel serum biomarker of testicular germ cell tumors: evidence for specificity from measurements in testicular vein blood and in neoplastic hydrocele fluid. Urol Int. 2016;97:76-83.

115. Flor I, Spiekermann M, Loning T, et al. Expression of microRNAs of C19MC in different histological types of testicular germ cell tumour. Cancer Genomics Proteomics. 2016;13:281-289.

116. Dieckmann KP, Radtke A, Spiekermann M, et al. Serum levels of microRNA miR-371a-3p: a sensitive and specific new biomarker for germ cell tumours. Eur Urol. 2017;71:213-220.

117. Dieckmann KP, Radtke A, Geczi L, et al. Serum levels of microRNA-371a-3p (M371 test) as a new biomarker of testicular germ cell tumors: results of a prospective multicentric study. J Clin Oncol. 2019;37:1412-1423.

118. Boellaard WPA, Gillis AJM, van Leenders G, et al. Cellular origin of microRNA-371a-3p in healthy males based on systematic urogenital tract tissue evaluation. Andrology. 2019;7:463-468. 